\title{
RPIFs to PDUCs: \\ New Planetary Data Utilization Centers to support NASA's Planetary Data Ecosystem
}

\author{
A WHITE PAPER TO THE NATIONAL RESEARCH COUNCIL \\ 2023-2032 PLANETARY SCIENCE AND ASTROBIOLOGY \\ DECADAL SURVEY
}

FINAL DRAFT: 30 June 2020

Lead author:

David A. Williams (Arizona State University, david.williams@asu.edu, 480-965-7045)

RPIF Directors and Colleague Coauthors (in alphabetical order):

Robert C. Anderson (NASA Jet Propulsion Laboratory, robert.c.anderson@jpl.nasa.gov)

Shane Byrne (University of Arizona, shane@lpl.arizona.edu)

Francois Costard (GEOPS, University of Paris Saclay, Orsay, France,

francois.costard@universite-paris-saclay.fr)

Alexander Hayes (Cornell University, hayes@astro.cornell.edu)

Ralf Jaumann (DLR, Berlin, Germany, ralf.jaumann@dlr.de)

Peter Mouginis-Mark (University of Hawaii, pmm@higp.hawaii.edu)

Jan-Peter Muller (University College London, j.muller@ucl.ac.uk)

Jürgen Oberst (DLR, Berlin, Germany, juergen.oberst@dlr.de)

Peter H. Schultz (Brown University, peter schultz@brown.edu)

John G. Spray (University of New Brunswick, Canada, jgs@unb.ca)

Julie Stopar (Lunar and Planetary Institute/USRA, stopar@1pi.usra.edu)

Sarah Sutton (University of Arizona, ssutton@1pl.arizona.edu)

Thomas R. Watters (Smithsonian Institution, WattersT@si.edu) 
1. Abstract. NASA's Regional Planetary Image Facility (RPIF) Network has effectively served the U.S. planetary science community for over 45 years. The RPIFs were originally conceived as libraries and research centers with reference collections of NASA mission photographic and digital image products, geologic maps, and planetary mission documents, literature, and legacy products. Their primary goal was to provide researchers, students, and media easy access to planetary image products and local planetary expertise, and to introduce the public to results from NASA's planetary missions and research through annual open houses. Now, as NASA considers a wholistic and efficient Planetary Data Ecosystem for the next decade and beyond, the network of facilities, data, and resources amassed within the RPIF Network can be efficiently and immediately leveraged and transformed to meet the evolving needs of the U.S. planetary science community. As the next generation of planetary scientists will rely more heavily on digital data from the PDS and other digital archives and tools to accomplish research, a new generation of Planetary Data Utilization Centers (PDUCs), created from members of the RPIFs, can serve as loci for enabling this research, as well as providing expertise, training, and products that supplement the PDS for the general science community. These centers would offer specialized training to use planetary data in geospatially-registered formats, including such software packages as JMARS, ISIS, ArcGIS, QGIS, Ames Stereo Pipeline as well as commercial offerings such as ENVI and SOCET SET, among others. Providing help to the general user to gain access to and process PDS data, including the more arcane data, would also be part of the PDUCs role, as well as hosting unique digital data sets to support future planetary research. These centers would facilitate assess and usability of existing and future digital planetary data, software, and tools; provide visualizations to better interpret planetary data; and ultimately bridge the gap between the PDS and the community of planetary data users.

2. Summary of the RPIFs: 1974-2020. NASA's Regional Planetary Image Facilities (RPIFs) were established by the NASA Planetary Geology and Geophysics Program to "maintain photographic and digital data as well as historic mission documentation" necessary to conduct planetary research. A prototype facility was established at the Lunar and Planetary Institute (Houston, Texas) in 1974. NASA then formally established a network of facilities throughout the US during the 1970s and 1980s with formal agreements that included significant leveraging by the host institutions (Table 1). International nodes were formed in the 1980s to foster data sharing and collaboration between NASA and international space programs. RPIF collections vary from institution to institution and may include photographic data (prints and film negatives) from the planetary missions of the 1960s-1990s (e.g., Lunar Orbiter, Apollo, Mariner 9, Mariner 10, Viking, Voyager, and Magellan) and digital data on CD-ROM from several missions (Magellan, Voyager, Galileo, Mars Global Surveyor). The individual specializations often reflect local expertise and/or mission involvement of researchers at the host institutions. Such data sets are not just historical artifacts but continue to be used by researchers due to their unique perspectives and easy access. They also are used for hands-on teaching and provide a resource for media inquiries, books (research and historical documents), and displays in various museums across the country.

Additionally, each RPIF node hosts its own unique collection of data accumulated by planetary scientists in their region, as well as rescued mission and research data sets (and literature) from retired investigators or closed centers. Over the course of the last decade, the RPIF nodes have each endeavored to digitize many of their unique document holdings and place them online at their individual institution websites, through RPIF funding, internal funding and 
via grants from various NASA programs ${ }^{1}$. In 2019, the NASA History Office reviewed all of the unique content of the nine US RPIFs, and a report was provided in April 2020 of high priority items requested by NASA to be digitized.

Table 1. Listing of the unique digital planetary data and materials collections and resources of some of the 17 active nodes of the RPIF Network.

\begin{tabular}{|c|c|c|}
\hline Node: Location & Data Set/Resource & Notes/Status \\
\hline Lunar \& Planetary Inst.: Houston & $\begin{array}{l}\text { Apollo Lunar Surface Experiments } \\
\text { Package technical reports and other } \\
\begin{array}{l}\text { Apollo-era } \\
\text { communications }\end{array} \\
\end{array}$ & $\begin{array}{l}\text { In person with some digitization } \\
\text { in progress }\end{array}$ \\
\hline CEPS: Smithsonian Inst., DC & $\begin{array}{l}\text { Planetary Radar Sounding (MARSIS, } \\
\text { SHARAD) }\end{array}$ & In person only \\
\hline NE Data Ctr.: Brown University & $\begin{array}{l}\text { 3D Printed landscapes, Bevan French } \\
\text { Reference collection. Earth-based } \\
\text { telescopic images. }\end{array}$ & $\begin{array}{l}\text { In person training. 3D printing } \\
\text { models on line. 3D printing } \\
\text { workshops. }\end{array}$ \\
\hline \multirow[t]{3}{*}{ SPIF: Cornell Un., Ithaca, NY } & GIS Laboratory/DTM production & In person and remote training \\
\hline & Meteorite museum & In person only \\
\hline & Virtual Field Experiences & In person and remote \\
\hline USGS, Flagstaff & Geologic mapping and GIS support & In person + online tutorials \\
\hline \multirow[t]{5}{*}{ Ronald Greeley Center: ASU, Tempe } & Planetary GIS Laboratory & In person training \\
\hline & Field analog terrains collection & $\begin{array}{l}\text { PDS archiving/Digitization in } \\
\text { progress }\end{array}$ \\
\hline & Lava tube database & Online w/supp. hardcopy \\
\hline & PAL*/aeolian experiment record & Limited digitization $^{1}$ \\
\hline & R. Greeley $35 \mathrm{~mm}$ slide collection & Digitization in progress \\
\hline \multirow[t]{4}{*}{ UArizona } & GIS Laboratory/DTM production & In person training \\
\hline & $\begin{array}{l}\text { Earth-based telescopic image } \\
\text { collection }\end{array}$ & \\
\hline & Lunar Surveyor image database & For delivery to PDS \\
\hline & $\begin{array}{l}\text { Communications of the Lunar and } \\
\text { Planetary Lab }\end{array}$ & Hosted online \\
\hline Jet Propulsion Lab., Pasadena & Historical planetary mission records & In person only \\
\hline \multirow[t]{3}{*}{ Un. Hawaii } & Clementine Mission Documentation & On-line searchable data base \\
\hline & $\sim 100$ MRO CTX DEMs & $\begin{array}{l}\text { On-line, with GUI and } \\
\text { supporting text }\end{array}$ \\
\hline & Three 3-D printers & $>120 *$.stl files on-line \\
\hline University College, London & $\begin{array}{l}\text { 3D imaging center for DTM } \\
\text { production. iMars webGIS of WMS } \\
\text { browse of } \approx 3000 \text { CTX DTMs, some } \\
\text { of the HRSC DTMs and all the UoA- } \\
\text { PDS, UCL and UoSeoul- HiRISE } \\
\text { DTMs. }\end{array}$ & $\begin{array}{l}\text { In person access to stereo } \\
\text { workstation (running USGS ISIS } \\
+ \text { SOCET) and large screen } \\
\text { MacPro and online access } \\
\text { through http://i-mars.eu/web- } \\
\text { gis.php }\end{array}$ \\
\hline Orsay, France & $\begin{array}{l}\text { Data from Lunar Orbiters, } \\
\text { Clementine, Mariner 6-7-9-10, Viking } \\
1-2 \text { (Orbiters et Landers), Mars } \\
\text { Pathfinder, Mars Global Surveyor, } \\
\text { Mars Odyssey, Venera 15-16, } \\
\text { Magellan, Voyager 1-2 and Galileo. } \\
\text { Planetary GIS laboratory, Interactive }\end{array}$ & In person access \\
\hline
\end{tabular}

1 e.g., Digitizing the Unique Photographic-Film Archive of the Ronald Greeley Center for Planetary Studies, PDART grant NNX15AI81G, 2015-2019, PI David Williams, ASU; Digitization and Public Archiving of the Surveyor Imaging Dataset, LASER grant number NNX14AQ11G, PI Shane Byrne, UArizona). 


\begin{tabular}{|l|l|l|}
\hline & $\begin{array}{l}\text { multi-user virtual reality of planet } \\
\text { Mars @ @ VR2Planets) }\end{array}$ & \\
\hline DLR, Berlin & $\begin{array}{l}\text { Data base for MarsExpress HRSC } \\
\text { images and Hayabusa2/MASCOT } \\
\text { images; 3D image arhive of NASA, } \\
\text { ESA and JAXA imaging data; Lunar } \\
\text { Orbiter and Viking image data base }\end{array}$ & $\begin{array}{l}\text { Data point within the German- } \\
\text { speaking area regarding images } \\
\text { from NASA, ESA and JAXA } \\
\text { missions }\end{array}$ \\
\hline $\begin{array}{l}\text { Planetay and Space Science Centre } \\
\text { (PASSC), New Brunswick, Canada }\end{array}$ & $\begin{array}{l}\text { 1. Earth Impact Database. 2. Impact } \\
\text { structure rock collections from } \\
\text { dozens of terrestrial craters. }\end{array}$ & $\begin{array}{l}\text { Digital and Online, including } \\
\text { maps, photos, images and impact } \\
\text { structure rock samples from } \\
\text { numerous impact structures }\end{array}$ \\
\hline
\end{tabular}

KEY: *NASA Planetary Aeolian Laboratory. ${ }^{1}$ Ten $16 \mathrm{~mm}$ films of 1990s Pismo Beach experiment (Greeley et al., 1996) digitized and online.

3. What has changed since the last decadal survey? The volume and handling of NASA Planetary Data and the need for an overarching support system. Over the course of the last decade, NASA and the US planetary science community directed more attention to the long-term usability of planetary data, looking beyond the PDS (which is a long-term storage archive of raw data and calibration files from NASA missions) in order to develop the concept of Planetary Spatial Data Infrastructures (PSDIs). PSDIs are structures that enable long-term usability of planetary data, typically data from multiple missions, in a geospatially registered format for each planetary object in the Solar System. PSDIs include not only the data themselves, but also the data accessibility, standards, and policies to enable their use, and the people with critical skills to engage and train non-experts in their use (Laura et al., 2018). MAPSIT, the Mapping and Planetary Spatial Infrastructure Team, is a NASA assessment group that was set up in 2014 to develop policy guidelines and recommendations for NASA in dealing with issues of long-term planetary data usability (see this website for definitions, details on PSDIs, and current recommendations: https://www.lpi.usra.edu/mapsit/). As study of the long-term challenges of enabling access and use of planetary spatial data have become apparent over the last decade, and with attention to MAPSIT's recommendations thus far, NASA Headquarters has developed an initiative called the Planetary Data Ecosystem, which is intended to be an overarching support network to help ensure standardization, discoverability, accessibility, and usability of planetary science data. In its nascent stages at present, NASA's Planetary Data Ecosystem review will be initiated in late 2020/early-2021.

Since 2005, the RPIF Network directors have recognized a key need in the US planetary science community for: 1) the training on how to access, create, and use planetary data, in particular geospatially-registered data from multiple missions, to conduct new research, and 2) a need to make accessible calibrated, higher-level digital data products from past planetary missions and NASA-funded research projects prior to the 2000s, that do not exist in the PDS, or are not appropriate for the PDS archive.

\section{Justification:}

First, training to use planetary data has been conducted mostly in an ad hoc manner, e.g., a senior staff researcher or graduate student trained a junior graduate student in data processing software; a student traveled to the USGS to learn ISIS (software for image processing) or SOCET SET (software to make digital terrain models). These training methods are not ideal in many circumstances (e.g., What if a student cannot travel to the USGS? What if a knowledgable student gets a job or a staff researcher retires and leaves before training a replacement?), and do not even help more senior scientists overcome the data processing barrier needed to work with a new mission or planetary target. To address this problem, in the 2010s the USGS supported a bi- 
annual series of Planetary Data Workshops both to offer training in some types of the software tools to use planetary data, and to assess needs for new planetary data tools and software in the community of data users. At this same time, several RPIFs also began conducting planetary data training events, both at their home institutions, and at national conferences (Table 2). Such training events at host institutions, however, were constrained by funding, e.g., local expertise could not be tapped without compensation.

Second, many historic planetary missions and major research projects developed higher-level products (e.g., mission-related thematic or geologic maps, such as NASA Dawn mission global geologic maps of (4) Vesta and (1) Ceres, or NASA-DOD Clementine data products, such as mission planning, sensor calibration charts, and orbit-by-orbit mission profile, Clementine 2 mission to Mars). Many of these data products were never intended for the PDS, or have incompatible formats, but are still useful to future researchers. These digital resources need to be curated in long-term institutional web archives (websites) with appropriate contextual information to enable future use.

Third, research often depends on multiple formats or synoptic views that may be available as hard-copy (mosaics and maps) within a facility, rather than recreated from scratch. The combination of on-line data with readily available reference products saves time and provides different perspectives.

Fourth, planetary research now involves combined data sets (imaging, remote sensing, and geophysics) that require multiple backgrounds and expertise for training and integration.

Based on the feedback we've received at training events thus far, we think this need for training in planetary data usability defines a new role for the RPIF nodes, to fill a necessary gap in the Planetary Data Ecosystem, which we call Planetary Data Utilization Centers.

Table 2. Partial list of planetary data utilization training events conducted by the nodes of the RPIF network during the last decade

\begin{tabular}{|l|c|c|}
\hline Training Event/Software & Date & Participating RPIF Nodes \\
\hline ArcGIS Training seminars, ASU Tempe & Fall, Spr 2015-2020 & ASU \\
\hline $\begin{array}{l}\text { Europlanet training workshop: 3D } \\
\text { facilities (http://www.i-mars.eu/rpif-3d- } \\
\text { workshop-jun2016.php). SOCET, ISIS, } \\
\text { CASP-GO, ACRO, Fledermaus }\end{array}$ & June 2016 \\
\hline 3D Landscape Printing Workshops & Jan 2017, Mar 2018 & Brown University \\
\hline ArcGIS Workshop at Cornell University & Feb. 2019, 2020 & Cornell \\
\hline Remote ArcGIS Workshops via Zoom & June 2020 & Cornell \\
\hline National Conferences & & Cornell, ASU, USGS \\
\hline ArcGIS Workshop, LPSC Houston & Mar 2018 & Cornell, ASU \\
\hline ArcGIS Workshop, LPSC Houston & Mar 2019 & ASU, Cornell \\
\hline ArcGIS Workshop, GSA Phoenix & Sep 2019 & \\
\hline
\end{tabular}

4. Planetary Data Utilization Centers (PDUCs). Our concept is to evolve the RPIFs into new Planetary Data Utilization Centers (PDUCs). The objectives of these PDUCs are very focused:

1) Conduct planetary data training events to communities of planetary data users in our respective geographic regions. The type of training offered is dependent upon the established expertise at each center and the needs of institutions within certain regions. Multiple PDUCs would continue to combine resources to conduct planetary data training events at national 
meetings (Table 2). These training events could be expanded to include the Division for Planetary Sciences (American Astronomical Society) and American Geophysical Union Annual Meetings, if desired. Working with the International nodes, these data training workshops could be extended to international meetings such as the European Planetary Science Conference (EPSC), the European Geophysical Union (EGU), and the European Lunar Symposium (ELS), for example. Regional training sessions would tap into the unique capabilities across the network using visiting trainers from other nodes and supplemental on-line sessions.

2) Maintain the unique digital data archives on our institutional websites for community access. For one example, the ASU PDUC, the Ronald Greeley Center for Planetary Studies, as a consequence of our 2015 PDART project, hosts PDS4-formated and reviewed, digitized field photographs on our website (https://rpif.asu.edu/field_image_archive/), essentially acting as a remote node of the PDS Geoscience Node. Because no website is everlasting without maintenance (security updates are periodically required, etc.), a small amout of support is required to maintain these websites as PDS-equivalent archives.

3) Maintain a set of computer workstations, and necessary equipment, software and, most importanty, expertise, that is not commonly available to individuals (or is too expensive), to enable digital planetary data training, use, and access for research. Training to use planetary data with existing software (NAIF SPICE, ISIS, JMARS, ArcGIS, Socet Set, Ames Stereo Pipeline, etc.) requires computer workstations as well as specialized equipment for data processing, digitiziation, geologic mapping, and making DTMs. Much of this infrastructure is already in place at most PDUC nodes, although computer workstations need to be replaced periodically. These resources will be available on-site, but can also be made available via remote screen sharing with real-time support for on-site staff.

4) Maintain resources to visualize digital planetary data. All 9 US PDUCs have a tabletop 22inch diameter MagicPlanet ${ }^{\mathrm{TM}}$ digital globe, given to them by NASA Headquarters in 2014-2015 (the UK has a 17-inch MagicPlanet ${ }^{\mathrm{TM}}$ ), to help visualize digital planetary data on a sphere. Also, some PDUCs have 3-D printers that can print models of planetary features using DEMs and shape models for various uses (e.g., Horowitz and Schultz, 2012). These resources should be maintained to enable the data utilization objective of these centers. Furthermore, these high-end workstations could be a bookable resource for Masters and $\mathrm{PhD}$ students, if they don't have access to such facilities elsewhere on campus.

5) Maintain and develop new resources to visualise $3 D$ digital planetary data using VR. Some US PDUCs (Cornell and Brown) have a COVE (Co-operative Visualisation Environment) and/or a state-of-the-art projection-based VR theater (YURT, using $69 \mathrm{HD}$ projectors), as well as the UK has an $8 \times 4$ foot Geowall screen and dual projectors to allow groups of planetary data users 3D visualisation experiences for training and research. In the future, more COVEs could be created for surface rover data visualisation alongside VR and AR technology in "safe spaces" for one to a few individuals individuals to work co-operatively. This includes virtual field geology tours to MER, MSL, M2020 and RFEXM22 landing sites as planned in the UK.

6) Generate new supporting materials from PDS data. Examples: The Hawaii PDUC has created $>100$ digital elevation models from MRO Context Camera images of Mars. These are presented in a similar manner to mission teams via clickable maps showing craters, volcanoes and other landforms on Mars (https:/www.higp.hawaii.edu/prpde/CTX_DEMs/toplevel.html). 
The Lunar and Planetary Institute's RPIF has generated a series of maps of the Moon's South Pole (2019-2020) to support current VIPER and Artemis planning and the next generation of lunar human exploration. The maps make use of recent LRO data sets and are presented as quick-look products that reduce data processing efforts for mission planners. Many of the online materials at the LPI RPIF website are quick-look, easily searchable digital products that have served many researchers and mission planners.

5. Why are PDUCs needed? Both at research universities and at NASA centers, planetary research is subject to loss of its "knowledge base" about planetary data and its usage because of the frequent graduation cycle of students, the departure of staff researchers as projects end, and faculty/senior researcher turnover due to institutional transfers, retirement, or death. Because these PDUCs by definition have trained individuals who know how to manipulate planetary data for research, they have a role in the Digital Age as "Data Utilization Centers", which "bridge the gap' between NASA's PDS (which stores planetary data, but does not provide "hands-on" training on how to use it) and the researchers and their students, who need the training to understand the data sets that are available for each planetary body, their coverage, format, etc., and how these data sets can be used with specific software for different types of research. Specifically:

1) PDUCs enable usability of PDS data: The Planetary Data System (PDS) is a digital storage archive, but the data therein are not immediately usable for many types of scientific studies by both experienced users and those who have no prior experience processing and working with planetary data. PDUCs contain trained staff to inform "customers" on how to find and extract PDS data and make them usable for scientific analysis. Staff members are typically trained, for example, to use Geographic Information Systems (GIS) software to enable spatial and temporal correlation of various planetary mission data sets so that users can conduct interdisciplinary studies via data fusion. They are also trained in the USGS' Integrated Software for Imagers and Spectrometers (ISISv3), which is the standard for image processing and mosaicking of digital images for most NASA and ESA planetary images. PDUC staff members are also trained in various other data acquisition and analysis tools (e.g., NAIF SPICE, JMARS, ENVI ${ }^{\circledR}$, etc.) to help users work with publically released planetary data. The importance of this technical support should not be underestimated, and PDUCs are often the only source for immediate help for students and professors at universities, smaller liberal arts colleges, or community colleges within a given region that do not have well-established planetary science programs or limited knowledge of PDS resources. Based on past experience with workshops, help involves hands-on training, not just remote learning, due to the range of experience levels and specific trouble shooting. Consequently, there is a need for regional nodes within a network of expertise.

2) PDUCs contain and produce higher-order data products: Most NASA missions produce derived data products (e.g., image mosaics of various extents; topical maps of specific features types, at scales varying from local to global; geological maps; or integrated data sets of grayscale/color images, spectral, radar, radiometric, stereo/topographic, or atmospheric information). These derived data products typically have not been released through the PDS. PDUCs typically collect these products to make them available to users. Most PDUCs also have the capability to use image processing software to produce derived data products, such as new digital elevation models that are not available from the mission teams.

3) PDUCs contain donated research holdings relevant to PSD activities: As most PDUCs are 
located at institutions that are heavily involved, if not leading, major NASA planetary missions, they often collect donations by local individuals (e.g., retiring faculty or scientists) or local companies that have unique planetary-related research materials, that would otherwise have been lost or destroyed and that are not digitally available. PDUCs have the resources to digitize these materials and make them publically available on their institutional websites, or through the PDS, which is relevant to ongoing and future planetary research.

6. Recommendations. Based on our experience during the past decade and the evolution of NASA's outlook and interest in maintaining the usability of planetary data, we recommend the following:

1) NASA continue development of the Planetary Data Ecosystem, building on the findings of MAPSIT, the PDS, and the RPIF network, particularly related to the development of planetary spatial data infrastructures to enable planetary research in coming decades.

2) As part of a vibrant Planetary Data Ecosystem, NASA enable a funding mechanism for Planetary Data Utilization Centers (PDUCs), new facilities that would leverage the resources of the old RPIF Network but focused on the objectives outlined above, most specifically 1) the training of users in planetary data, 2) making accessible new digital data sets from past planetary missions and historic planetary research projects, and 3) producing new online supporting materials (e.g., derived data sets such as DTMs, "user guides" to PDS data formats, etc.). PDUCs would thus serve as "community memory" for mission documentation and methodologies. NASA should encourage cost sharing with host institutions, who were eager participants in the RPIF network for several decades.

3) NASA, through the Planetary Data Ecosystem, enable better communication between the PDS nodes and the PDUCs. PDUCs are uniquely able to capture community feedback on PDS resources such as data search tools, that could enable the PDS to improve its services.

4). Support PDUCs in providing (or co-hosting) multiple planetary data users workshops targeting researchers and students at institutions across a given region. Local and visiting facilitators (e.g., USGS, nearby institutions with unique expertise) would schedule the workshops according to need and demand.

5) Encourage and support the exchange of data between the US and international centers in terms of capturing areas of expertise within the Planetary Data Ecosystem.

\section{References:}

Greeley, R., Blumberg, D.G., and Williams, S.H., 1996. Field measurements of the flux and speed of wind-blown sand. Sedimentology, 43, 41-52.

Horowitz, S. and Schultz, P. H. (2014), Printing Space: Using 3D Printing of Digital Terrain Models in Geosciences Education and Research, Journal of Geoscience Education 62, 138145.

Laura, J.R., Bland, M. T., Fergason, R. L., Hare, T. M., and Archinal, B. A., 2018. Framework for the development of Planetary Spatial Data Infrastructures: A Europa case study. Earth and Space Science, 5(9), 486-502 